Jurnal Qua Teknika, Vol. 7 No. 2 September 2017

ISSN 2088 2424(cetak); 2527 3892(elektronik)

UNISBA Blitar, Http:// qua.unisbablitar.ejournal.web.id

Chaerul Arifin, Bambang Satriyo Purwito, Ahmad Sholihuddin. 2017. Studi Analisa Penempatan

Transformator Distribusi Berdasarkan Beban Lebih di PT. PLN (Persero) Area Kediri UPJ Rayon Srengat Blitar. Jurnal Qua Teknika, (2017), 7(2):1 15.

\title{
STUDI ANALISA PENEMPATAN TRANSFORMATOR DISTRIBUSI BERDASARKAN BEBAN LEBIH DI PT. PLN (PERSERO) AREA KEDIRI UPJ RAYON SRENGAT BLITAR
}

\author{
Chaerul Arifin 1), Bambang Satriyo Purwito, Ahmad Sholihuddin \\ Fakultas Teknik, Universitas Islam Balitar \\ ${ }^{1}$ email: carifin7@gmail.com
}

\begin{abstract}
Abstrak
Salah satu komponen utama yang sangat berperan dalam suatu sistem tenaga listrik adalah transformator distribusi. Secara umum biaya pembelian transformator distribusi sekitar $10 \%$ dari biaya untuk pengadaan suatu distribusi.

Sistem distribusi yang ada Di PT. PLN (Persero) Area Kediri UPJ Rayon SrengatBlitar terdapat 4 penyulang yaitu penyulang Srengat, Maliran, Penataran, Bendosari. Daerah Kecamatan Ponggok dilayani oleh Penyulang Maliran dan Penataran, kecamatan Srengat dilayani oleh penyulang Srengat dan Bendosari, kecamatan Wonodadi dilayani Srengat dan Bendosari, dan kecamatan Udanawu dilayani Srengat dan Maliran. Dengan jumlah Trafo pada tahun 2013, 235 buah (25745) dan pada tahun 2016 Mei 252 buah (28595).

Laju pertumbuhan beban transformator distribusi yang ada di PT. PLN Srengat pada tahun 2013 adalah pada Januari-Februari mengalami peningkatan 0,38 \%, bulan Mei-Juni mengalami peningkatan 0,58\%, bulan September-Oktober mengalami peningkatan 1,14\%, pada tahun 2014 hanya dua kali peningkatan bulan Maret-April 0,94\% dan bulan September-Oktober 0,36\%. Pada tahun 2015 bulan Mei-Juni mengalami peningkatan 0,69\%, pada bulan Juli-Agustus mengalami penurunan 0,97\%, September-Oktober 1,71\%. Pada tahun 2016 bulan Maret-April mengalami peningkatan 0,26\% dan pada bulan April mengalami peningkatan 0,77\%..
\end{abstract}

\section{Kata kunci: Distribusi, Pergantian Transformator}

\section{PENDAHULUAN [Times New Roman 12 bold]}

Listrik merupakan suatu kebutuhan yang sangat penting bagi manusia dan kehidupan di abad modern ini. Manfaat yang terbesar dari listrik terlihat nyata dalam berbagai aspek kehidupan manusia. Kemajuan yang pesat dibidang teknologi dan perkembangan sektor industri, disertai pertumbuhan penduduk dan kenaikan taraf hidup, menyebabkan makin meningkatnya kebutuhan tenaga listrik. Salah satu komponen utama yang sangat berperan dalam suatu sistem tenaga listrik adalah transformator distribusi. Secara umum biaya pembelian/pemakian transformator distribusi minimal sekitar $10 \%$ dari biaya untuk pengadaan suatu distribusi dan maksimal $80 \%$.

Penulisan artikel dengan judul Studi Analisa Penempatan Transformator Distribusi Berdasarkan Beban Lebih Di PT. PLN (Persero) Area Kediri UPJ Rayon Srengat Blitar. Merupakan obyek yang harus dianalisa karena didaerah tersebut transformatornya mengalami beban lebih dikarenakan banyaknya konsumen (industri/pabrik, rumah-rumah, dan lain-lain). Transformator merupakan suatu alat listrik yang dapat memindahkan dan mengubah tegangan arus bolak-balik dari satu tingkat ketingkat yang lain.

Untuk merencanakan penggantian transformator distribusi pada suatu distribusi, maka perlu diketahui terlebih dahulu beberapa informasi tentang hal tersebut, yaitu: a) Beban yang 
dilayani oleh transformator distribusi selama beberapa waktu yang lalu. b) Kapasitas transformator distribusi dan beban pada saat ini. c) Keadaan umum sistem distribusi dimana distribusi itu berada.

Artikel ini memaparkan jumlah beban yang dibutuhkan. Harapan penulisan artikel ini dapat mengulas dengan jelas dan tepat tanpa mengurangi esensi dari sumber yang telah dipakai.

Berdasarkan pemaparan tersebut maka dapat dirumuskan tujuan sebagai berikut: 1) Memprediksi pertumbuhan beban yang dialami oleh transformator distribusi. 2) Menghitung pengaman/fuselink yang dipasang. 3) Cara mengatisipasi beban lebih yang dialami oleh transformator distribusi.

Agar tujuan penulisan terfokus maka peneliti permasalahan dibatasi sebagai berikut : 1) Menganalisa sebab Transformator distribusi diganti. 2) Prediksi pertumbuhan beban transformator distribusi hanya wilayah srengat. 3) Pembahasan/menentukan jumlah beban pada area tersebut dan spesifikasi transformator yang dibutuhkan.

Dengan adanya artikel ini diharapakan pembaca mendapatkan pengertian dan penjelasan mengenai beban transformator distribusi yang harus dipasang dan sebagai informasi ilmiah bagi peneliti yang akan mengadakan penelitian terhadap masalah yang sama pada masa yang akan datang.

\section{KAJIAN LITERATUR}

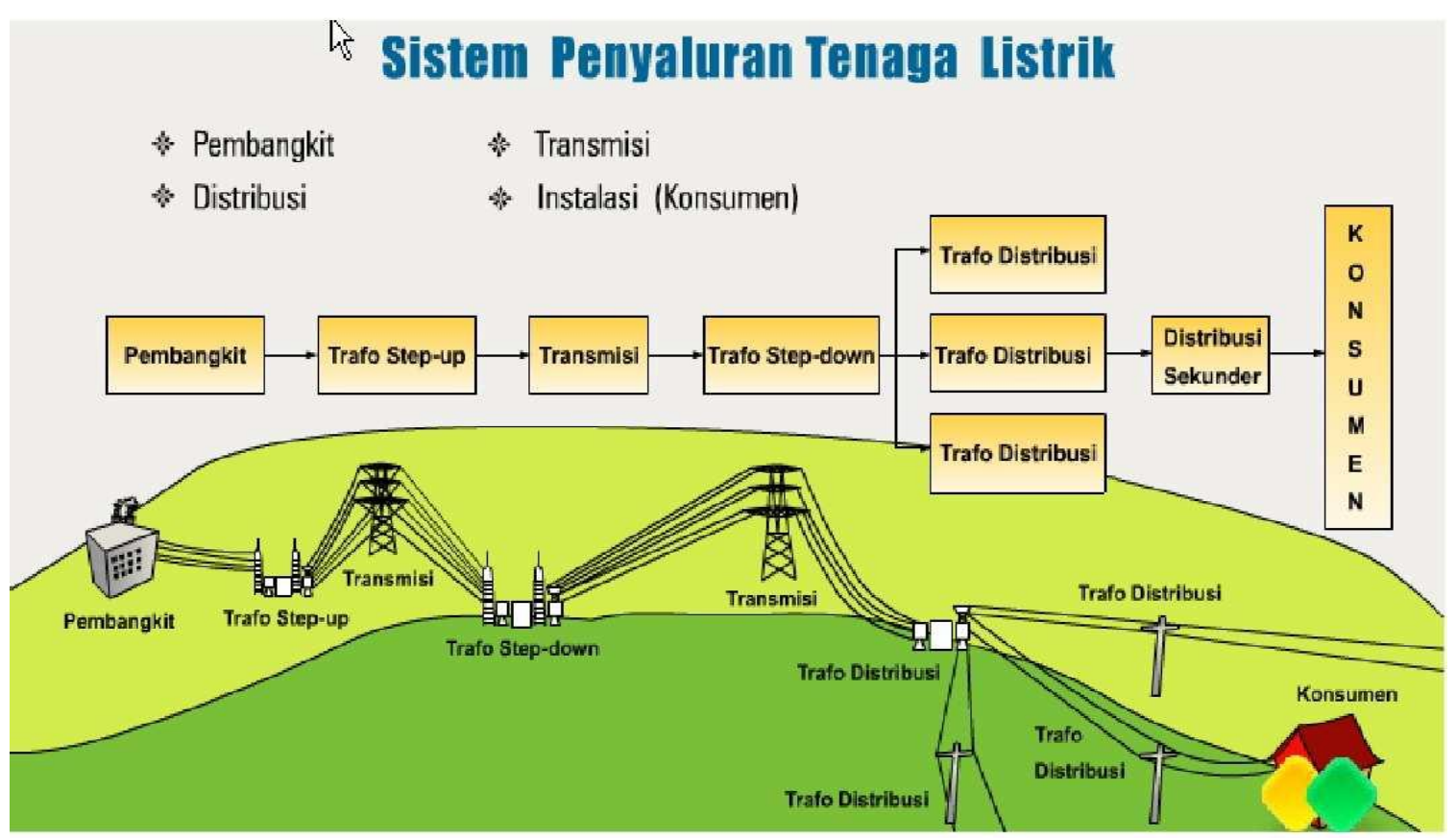

Gambar 2.1 Sistem Penyaluran Tenaga Listrik ${ }^{[1]}$

\subsection{Sistem Distribusi Tenaga Listrik ${ }^{[2]}$}

Secara umum sistem tenaga listrik tersusun atas tiga subsistem pokok yaitu: Subsistem Pembangkit, Subsistem Transmisi dan Subsistem Distribusi.

Sistem pembangkit merupakan sistem yang berfungsi sebagai pembangkit tenaga listrik. Tenaga listrik yang dibangkitkan kemudian ditransmisikan dalam daya yang besar oleh sistem transmisi ke gardu induk transmisi (GI). Dari GI transmisi tenaga listrik disubtransmisikan 
ke GI distribusi, kemudian didistribusikan kepada pelanggan secara langsung dan ke gardugardu distribusi untuk keperluan pelanggan dengan daya dan tegangan rendah.

Dalam perencanaan sistem tenaga listrik, sistem pembangkit dan sistem transmisi saling berhubungan secara ekonomis dalam pemilihan lokasi, desain, dan hubungan skala ekonomi.

Sistem Distribusi tenaga listrik merupakan bagian dari sistem tenaga listrik yang menghubungkan energi listrik dari gardu induk bertegangan menengah ke konsumen. Fungsi utama sistem distribusi adalah menyalurkan tenaga listrik dari sumber daya ke konsumen. Sumber daya tersebut dapat berupa :

a. Pusat pembangkit listrik yang langsung berhubungan dengan jaringan distribusi.

b. Gardu induk, yaitu gardu yang disuplai melalui pembangkit listrik melalui jaringan transmisi dan sub transmisi. Salah satu fungsi dari gardu induk adalah mensuplai tenga listrik ke konsumen yang terletak jauh dari pusat pembangkit tenaga listrik.

Baik buruknya suatu sistem distribusi dinilai dari beberapa faktor yaitu : Regulasi tegangan (Jatuh Tegangan), Kontinuitas pelayanan, Efisiensi dan Harga sistem.

Suatu sistem distribusi harus memenuhi beberapa persyaratan sebagai berikut :

a. Regulasi tegangan tidak terlalu besar

b. Gangguan terhadap pelayanana tidak boleh terlalu lama

c. Biaya sistem tidak terlalu mahal

Bagian-bagian dari sistem tenaga listrik, yaitu :

1. Sistem distribusi primer, yaitu sistem tenaga listrik dari gardu induk transmisi ke gardu induk subtransmisi. Jaringan ini merupakan tegangan menegah (TM)

2. Sistem distribusi sekunder, yaitu sistem tenaga listrik yang menyalurkan daya listrik dari subtransmisi ke gardu induk distribusi. Jaringan ini merupakan tegangan rendah (TR).

Setelah saluran transmisi mendekati pusat pemakaian tenaga listrik, yang dapat merupakan suatu daerah industri atau suatu kota. Tegangan melalui gardu induk (GI) diturunkan menjadi tegangan menengah (TM) $20 \mathrm{KV}$. Setiap gardu induk (GI) sesungguhnya merupakan pusat beban untuk suatu daerah pelanggan tertentu, bebannya berubah-ubah sepanjang waktu sehingga daya yang di bangkitkan dalam pusat-pusat listrik harus selalu berubah. Perubahan daya yang dilakukan di pusat pembangkit ini bertujuan untuk mempertahankan tenaga listrik tetap pada frekuensi 50Hz. Proses perubahan ini dikoordinasikan dengan Pusat Pengaturan Beban (P3B).

Tegangan menengah dari gardu induk (GI) ini melalui saluran distribusi primer, untuk disalurkan ke gardu-gardu distribusi (GD) atau pemakai tegangan menengah (TM). Dari saluran distribusi primer, tegangan menegah (TM) diturunkan menjadi tegangan rendah (TR) 220V/380 V melalui gardu distribusi (GD). Tegangan rendah dari gardu distribusi disalurkan melalui saluran tegangan rendah ke konsumen tegangan rendah.

\subsection{Gardu Distribusi ${ }^{[3]}$}

Gardu distribusi adalah suatu tempat/bangunan instalasi yang didalamnya terdapat alatalat : pemutus, penghubung, pengaman dan transformator distribusi untuk mendistribusikan tenaga listrik sesuai dengan kebutuhan tegangan konsumen.

Peralatan ini berfungsi untuk menunjang mencapai pendistribusian tenaga listrik secara baik yang mencangkup koinunitas pelayanan yang terjamin, mutu yang tinggi dan menjamin keselamatan bagi manusia. Fungsi gardu distribusi adalah sebagai berikut :

1. Menyalurkan/meneruskan tenaga listrik tegangan menengah ke konsumen tegangan rendah . 
2. Menurunkan tegangan menengah menjadi tegangan rendah selanjutnya disalurkan ke konsumen tegangan rendah.

3. Menyalurkan/meneruskan tenaga listrik tegangan menengah ke gardu distribusi lainya dan ke gardu hubung.

Gardu listrik pada dasarnya adalah rangkian dari suatu perlengkapan hubung bagi PHB tegangan menengah dan PHB tegangan rendah. Masing-masing dilengkapi gawai-gawai kendali dengan komponen proteksinya. Jenis-jenis gardu listrik atau gardu distribusi didesain berdasarkan maksud dan tujuan penggunaannya sesuai dengan peraturan pemda setempat, yaitu :

1. Gardu distribusi konstruksi beton (gardu beton)

2. Gardu distribusi kontruksi metal clad ( gardu besi )

3. Gardu distribusi tipe tiang portal, dan distribusi tipe tiang cantol (gardu tiang)

4. Gardu distribusi mobil tipe kios, dan gardu distribusi mobil tipe trailer (gardu mobil).

Komponen-komponen pada gardu distribusi :

1. PHB sisi tegangan rendah

2. PHB pemisah saklar daya

3. PHB pengaman transformator

4. PHB sisi tegangan rendah

5. Pengaman tegangan rendah

6. Sistem pembumian

7. Alat-alat indikator

Instalasi perlengkapan hubung bagi tegangan rendah berupa PHB TR atau rak TR terdiri dari 3 bagia yaitu : Sirkuit masuk + saklar, Rel pembagi, Sirkuit keluar + pengaman lebur maksimum 8 sirkit.

Spesifikasi mengikuti kapasitas transformator distribusi yang dipakai. Instalasi kabel daya dan kabel kontrol, yaitu KHA kabel daya antara kubikel ke transformator minimal 125\% arus beban nominal transformator. Pada beben kontruksi memakai kubikel TM single core $\mathrm{Cu} 3 \times 1 \times 25 \mathrm{~mm}^{2}$ atau $3 \times 1 \times 35 \mathrm{~mm}^{2}$. Antara transformator dengan Rak TR memakai kabel daya dengan KHA $125 \%$ arus nominal. Pada beberapa instalasi memakai kabel inti tunggal masing-masing kabel perfasa, $\mathrm{Cu} 2 \times 3 \times 1 \times 240 \mathrm{~mm}^{2}+1 \times 240 \mathrm{~mm}^{2}$.

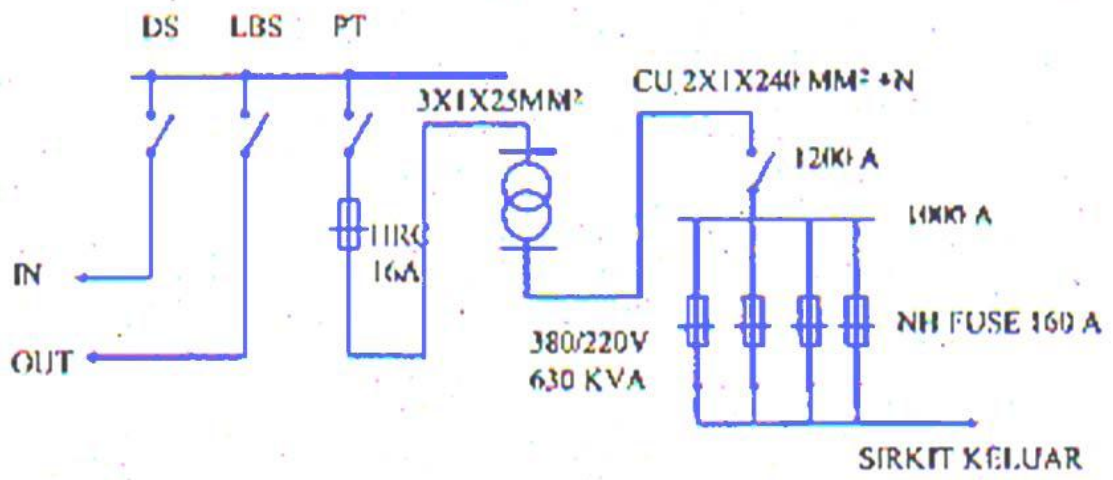

Gambar 2.2 Contoh Monogram Gardu Distribusi, (Ca. Lestari,2015) ${ }^{[3]}$

Instalasi lain yang ada pada gardu distribusi adalah Instalasi penerangan, terdiri dari :

1. Instalasi alat pembatas dan pengukur

2. Instalasi kabel scada untuk kubikel dengan motor kontrol. 
3. Instalasi pengaman pelanggan untuk APP pelanggan tegangan menengah

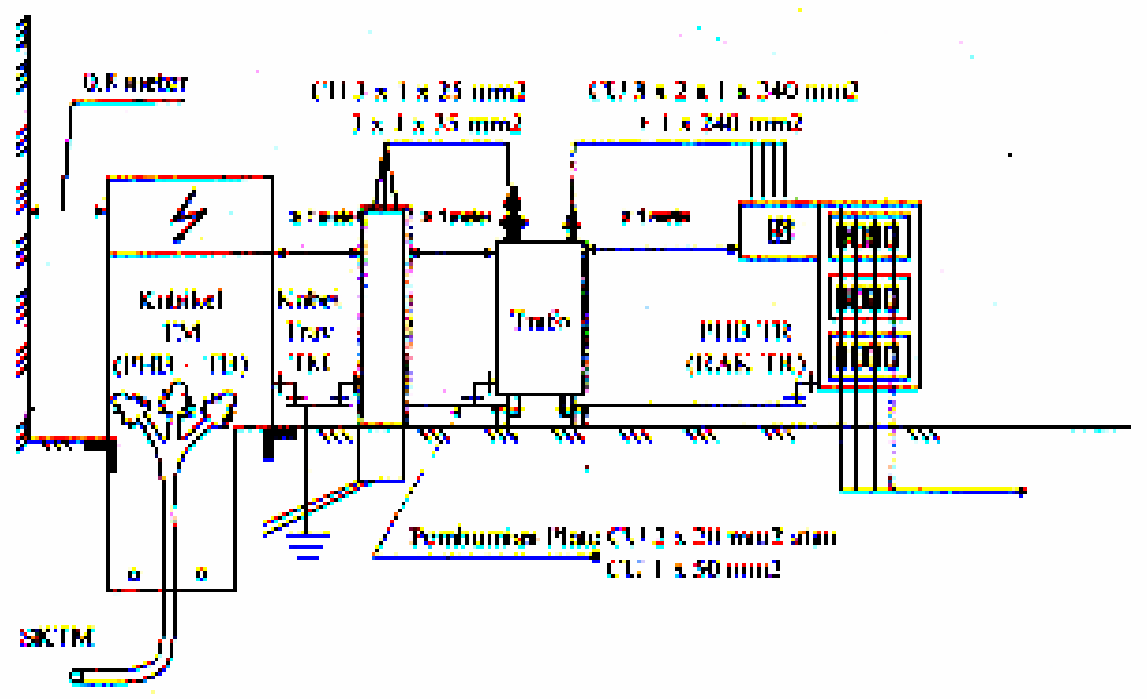

Gambar 2.3 Penampang Fisik Gardu Distribusi, (Ca.Lestari,2015) ${ }^{[3]}$

\subsection{Gardu Distribusi Tiang Tipe Portal ${ }^{[3]}$}

Gardu Portal adalah gardu listrik tipe terbuka (out dor) dengan memakai kontruksi 2 tiang atau lebih. Tempat kedudukan transformator sekurang-kurangnya 3 meter diatas tanah dan ditambahkan platform sebagai fasilitas kemudahan kerja teknisi operasi dan pemeliharaan. Transformator dipasang pada bagian atas dan lemari panel/PHB-TR pada bagian bawah

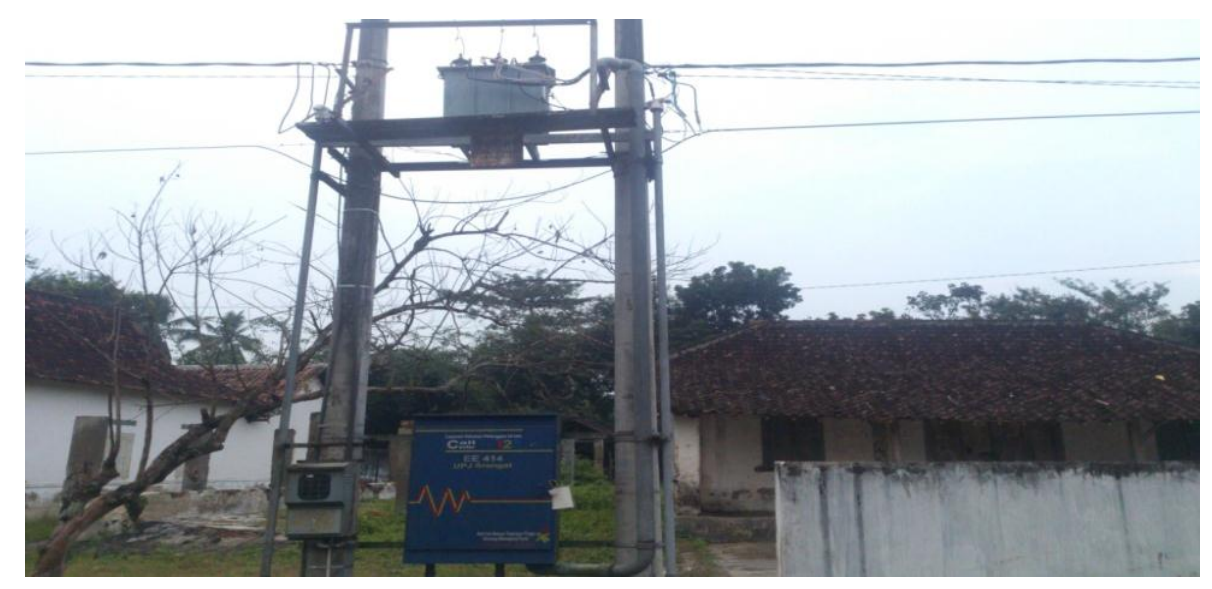

Gambar 2.4 Gardu distribusi tiang tipe portal 


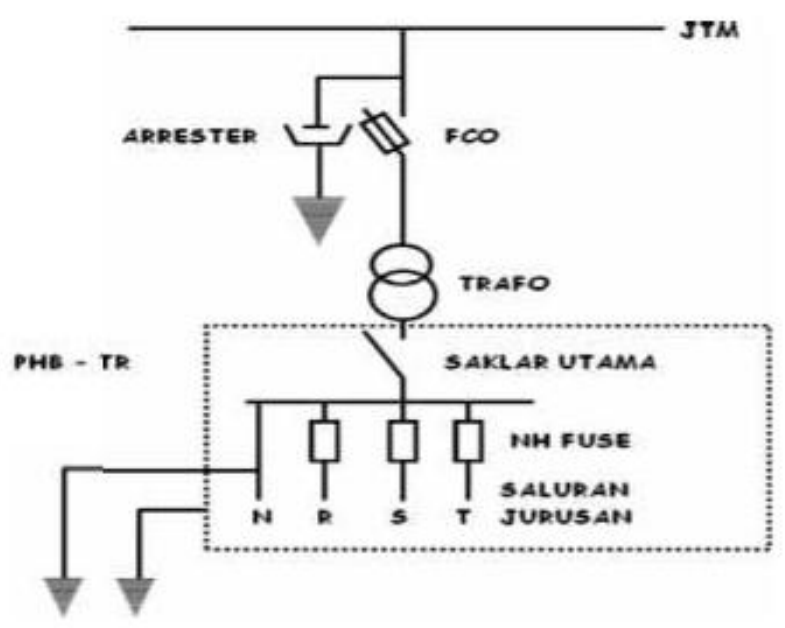

Gambar 2.5 Diagram satu garis distribusi tiang tipe portal, (Ca.Lestari,2015) ${ }^{[3]}$

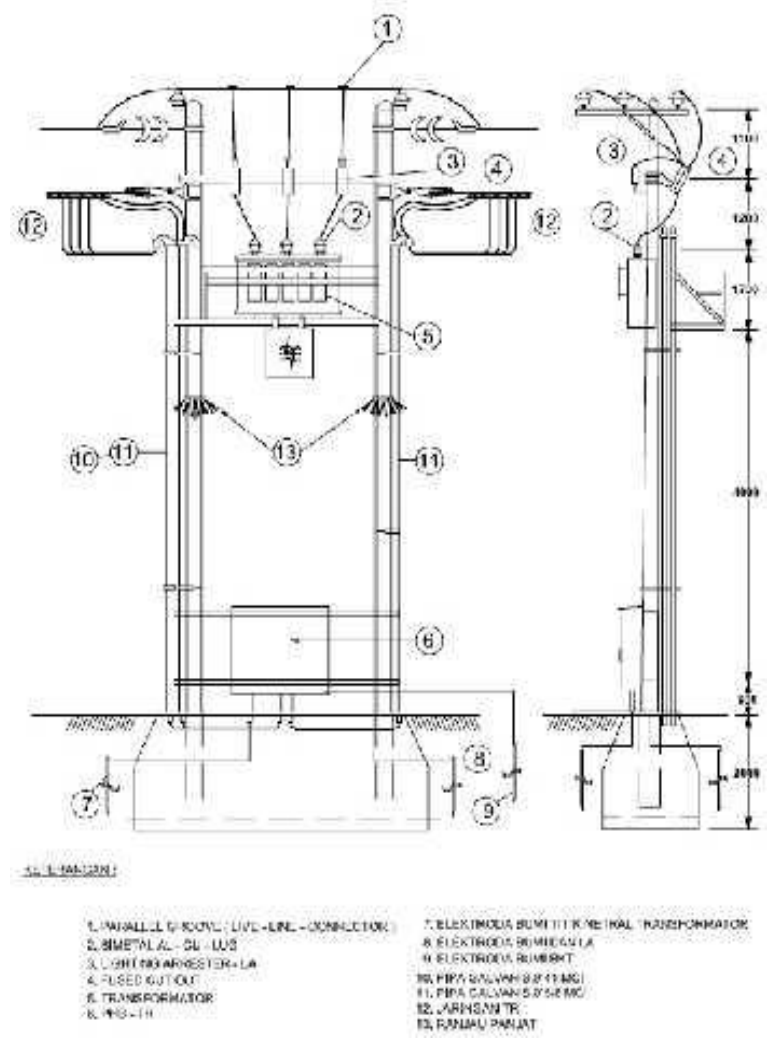

Gambar 2.6 Kontruksi gardu distribusi tiang tipe portal (Ca.Lestari,2015) ${ }^{[3]}$

\subsection{Peralatan Listrik Pada Gardu Tiang Tipe Portal ${ }^{[5]}$}

1. Peralatan Hubung :
a. fuse cut out $20 \mathrm{KV}$
b. saklar pada rak TR

2. Peralatan Proteksi

a. fuse cut out $20 \mathrm{kv}$

b. lightning arrester 


\section{c. $\mathrm{NH}$ fuse}

3. Kabel / penghantar
a. Kawat penghubung dari jaring ke fuse cut out
b. Kawat penghubung dari fuse cut out ke transformator
c. Kabel penghubung dari transformator ke rak TR
d. Kabel keluar

4. Pentanahan
a. Pentanahan kerangka/body peralatan
b. Pentanahan netral sisi tegangan rendah transformator
c. Pentanahan arrester

\section{METODE PENELITIAN}

\subsection{Tempat dan Waktu Penelitian}

Tempat pelaksanaan penelitian adalah di PT. PLN (Persero) Area Kediri Sub Rayon Srengat yang beralamat Jalan Raya No.19 Srengat Blitar oleh mahasiswa Universitas Islam Balitar Periode tahun 2016 dilaksanakan selama 1 bulan pada tanggal 9 April sampai dengan 7 Mei 2016.

\subsection{Prosedur Penelitian}

Prosedur Penelitian dalam penulisan laporan karya ilmiah ini adalah metode observasi partisipan dimana peneliti berperan ganda, yaitu sebagai pengamat sekaligus bagian yang diamati. Dalam penelitian ini yang dilakukan penulis ini adalah mengetahui jumlah beban yang dibutuhkan untuk distribusi/untuk pengoprasian, supaya beban tersebut tidak lebih (over load)

Dalam penulisan laporan tugas akhir ini penulis menggunakan metode penulisan yang meliputi :

1. Metode Observasi, yaitu pengumpulan data di lakukan langsung dari pengamatan dan pencatatan dilapangan.

2. Metode Interview, yaitu pengumpulan data dilakukan dengan cara menanyakan langsung kepada narasumber.

3. Metode kepustakaan, yaitu pengumpulan data dilakukan dengan cara data diambil atau dikumpulkan dari buku-buku yang terkait dengan pelaksanaan penelitian.

\subsection{Metode Analisis Data ${ }^{[4]}$}

Penentuan kapasitas dari sebuah transformatorharus berdasarkan beban yang dilayani. Dalam hal ini persentasi pembebanan transformator harus mendekati 80\% kapasitas transformator. Transformator umumnya mencapai efisiensi maksimum (rugi-rugi trafo minimum) dan persamaan 3 merupakan formula yang dapat digunakan untuk perhitungan rating transformator yang dipilih, (Warman, 2004):

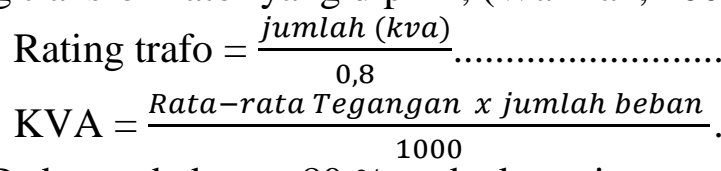

Pada pembebanan $80 \%$ maka kapasitas transformator adalah :

$$
\begin{aligned}
& =\frac{100 \%}{0.8} \text {. } \\
& \text { Dengan : } \\
& \text { MVA = Beban transformator }
\end{aligned}
$$




\section{$\mathrm{X}=$ Kapasitas transformator}

\subsubsection{Pembebanan Transformator ${ }^{[4]}$}

Menurut PT PLN ( Persero), transformator distribusi diusahakan agar tidak dibebani lebih dari $80 \%$ atau dibawah $40 \%$, jika melebihi atau kurang dari nilai tersebut transformator bisa dikatakan overload atau underload. Diusahakan agar transformator tidak dibebani keluar dari range tersebut. Bila beban transformator terlalu besar maka dilakukan penggantian transformator atau penyisipan transformator atau mutasi trasformator. Rumus berikut dapat digunakan untuk melihat besar kapasitas transformatorn yang ada.

$$
\begin{aligned}
& \mathrm{KVA} \text { beban }=\left(\mathrm{I}_{\mathrm{R}} \mathrm{X} \mathrm{V}_{\mathrm{R}-\mathrm{N}}\right)+\left(\mathrm{I}_{\mathrm{S}} \mathrm{X} \mathrm{V}_{\mathrm{S}-\mathrm{N}}\right)+\left(\mathrm{I}_{\mathrm{T}} \mathrm{X} \mathrm{V}_{\mathrm{T}-\mathrm{N}}\right) . . \\
& \% \text { Persentase beban transformator }=\frac{\text { kva beban }}{\text { kva trafo }} \times 100 \%
\end{aligned}
$$

Perkiraan pada bulan Mei sampai juni 2016 di penyulang Srengat Kecamatan Ponggok mengalami kekurangan beban sekitar 81000 VA. Maka perencanaan yang akan dibutuhkan memakai rumus sebagai berikut:

$$
\mathrm{KVA}=\frac{900 \times 90}{1000}=81 \mathrm{KVA} \text {. }
$$

Pemilihan kapasitas KVA trafo distribusi didasarkan pada beban yang akan dilayani diusahakan presentasi pembebanan trafo distribusi mendekati $80 \%$. Trafo distribusi umumnya mencapai efesiensi maksimum (rugi-rugi trafo minimum). Bila beban trafo terlalu besar, maka dilakukan penggantian trafo atau penyisipan trafo atau mutasi trafo (trafo yang melayani beban kecil dimutasikan ke beban yang besar, dan begitu sebaliknya). Mutasi antar trafo dapat dilakukan setelah hasil pengukuran beban diperoleh, rumus beikut dapat digunakan untuk perhitungan rating trafo distribusi yang dipilih.

$$
\text { Rating trafo distribusi }=\frac{K V A \text { Beban }(K V A)}{0,8}
$$

Pilih rating trafo distribusi yang sebenarnya yang (tersedia) yang mendekati hasil perhitungan dari rumus diatas. Contoh : Untuk potensi beban 150 KVA, perhitungan rating trafo distribusi.

$$
\text { Rating trafo distribusi }=\frac{75(\mathrm{KVA})}{0,8}=93,75 \mathrm{KVA}
$$

Maka dapat diperoleh rating trafo distribusi yang tersedia 93,75 KVA maka yang terpasang $100 \mathrm{KVA}$.

\subsubsection{Menghitung Fusling/NH}

Untuk pengaman trafo dalam peralatan listrik tentu ada berbagai macam pengaman beban lebih. di antaranya adalah Fuse Link. fuse link ini befungsi untuk pengaman arus lebih pada TM (tegangan menengah) dan juga di gunakan pada pengaman trafo atau transformator. 


\section{Rumus:}

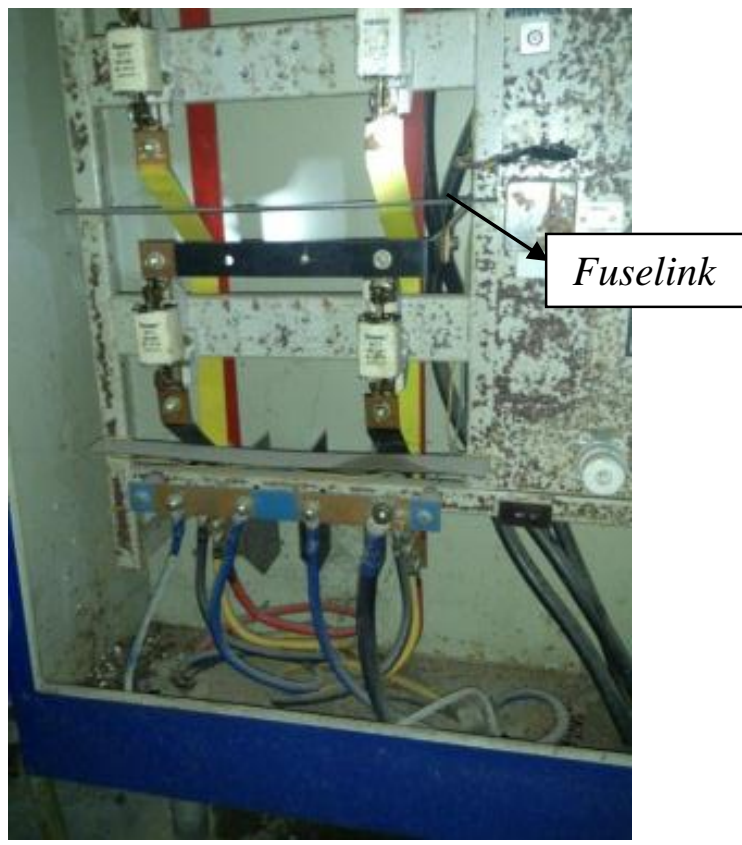

Gambar 3.1 FuseLink

Fuse link $=\frac{P}{V x \sqrt{3}}$

NH Fuse umumnya dipasang pada PHB trafo listrik yang berfungsi sebagai pemutus atau pengaman terhadap arus lebih. Cara menghitung berapa Ampere NH Fuse yang harus dipasang adalah sebagai berikut:

$$
\begin{aligned}
& \mathrm{I}=\mathrm{P} / \mathrm{V} \times 1.73(\sqrt{3}) \\
& \mathrm{I}=\operatorname{Arus}(\mathrm{A}) \\
& \mathrm{P}=\text { Daya }(\mathrm{VA}) \\
& \mathrm{V}=\text { Tegangan }(\text { Volt })=400 \text { volt tegangan } \mathrm{TR} \\
& \text { Contohnya }=\text { Jika trafo yang terpasang } 100 \mathrm{KVA}=100.000 \mathrm{VA} \text {, maka NH } \\
& \text { Fuse yang terpasang adalah: } \\
& \mathbf{I}=\frac{\mathbf{1 0 0 0 0 0}}{\mathbf{4 0 0} \times \mathbf{1 , 7 3}}=144.5 \mathrm{~A}
\end{aligned}
$$

\section{HASIL DAN PEMBAHASAN}

\subsection{Hasil}

Bagian ini menyajikan hasil penelitian. Hasil penelitian dapat dilengkapi dengan tabel, grafik (gambar), dan/atau bagan. Bagian pembahasan memaparkan hasil pengolahan data, menginterpretasikan penemuan secara logis, mengaitkan dengan sumber rujukan yang relevan. [Times New Roman, 12, normal].

Perkiraan laju pertumbuhan Daya (KVA) pada transformator distribusi di PT. PLN (Persero) Area Kediri UPJ Rayon Srengat, pada tahun 2013 sampai tahun 2016 yaitu sebagai berikut :

\section{Tabel Data Jumlah Transformator Distribusi Di PT. PLN (Persero) Area Kediri UPJ Rayon Srengat Blitar Tahun 2013-2016 ${ }^{[5]}$}


Jurnal Qua Teknika, Vol. 7 No. 2 September 2017

ISSN 2088 2424(cetak); 2527 3892(elektronik)

UNISBA Blitar, Http://qua.unisbablitar.ejournal.web.id

Chaerul Arifin, Bambang Satriyo Purwito, Ahmad Sholihuddin. 2017. Studi Analisa Penempatan

Transformator Distribusi Berdasarkan Beban Lebih di PT. PLN (Persero) Area Kediri UPJ Rayon Srengat Blitar. Jurnal Qua Teknika, (2017), 7(2):1 15.

\begin{tabular}{|c|c|c|c|c|c|c|}
\hline \multirow{2}{*}{ NO } & \multirow{2}{*}{ BULAN } & \multirow{2}{*}{ JUMLAH } & \multicolumn{4}{|c|}{ TAHUN } \\
\hline & & & 2013 & 2014 & 2015 & 2016 \\
\hline \multirow{2}{*}{1} & \multirow{2}{*}{ JANUARI } & BUAH & 235 & 242 & 247 & 251 \\
\hline & & KVA & 25.745 & 26.555 & 27.265 & 28.325 \\
\hline \multirow{2}{*}{2} & \multirow{2}{*}{ FEBRUARI } & BUAH & 236 & 242 & 247 & 251 \\
\hline & & KVA & 25.845 & 26.555 & 27.265 & 28.325 \\
\hline \multirow{2}{*}{3} & \multirow{2}{*}{ MARET } & BUAH & 236 & 242 & 247 & 251 \\
\hline & & KVA & 25.845 & 26.555 & 27.265 & 28.300 \\
\hline \multirow{2}{*}{4} & \multirow{2}{*}{ APRIL } & BUAH & 236 & 243 & 247 & 251 \\
\hline & & KVA & 25.845 & 26.805 & 27.265 & 28.375 \\
\hline \multirow{2}{*}{5} & \multirow{2}{*}{ MEI } & BUAH & 238 & 246 & 247 & 252 \\
\hline & & KVA & 25.995 & 27.165 & 27.265 & 28.595 \\
\hline \multirow{2}{*}{6} & \multirow{2}{*}{ JUNI } & BUAH & 238 & 246 & 248 & \\
\hline & & KVA & 25.995 & 27.165 & 27.455 & \\
\hline \multirow[b]{2}{*}{7} & \multirow{2}{*}{ JULI } & BUAH & 239 & 246 & 249 & \\
\hline & & KVA & 26.095 & 27.165 & 27.615 & \\
\hline \multirow{2}{*}{8} & \multirow{2}{*}{ AGUSTUS } & BUAH & 239 & 246 & 248 & \\
\hline & & KVA & 26.095 & 27.165 & 27.345 & \\
\hline \multirow{2}{*}{9} & \multirow{2}{*}{ SEPTEMBER } & BUAH & 239 & 246 & 249 & \\
\hline & & KVA & 26.095 & 27.165 & 27.445 & \\
\hline \multirow{2}{*}{10} & \multirow{2}{*}{ OKTOBER } & BUAH & 241 & 247 & 249 & \\
\hline & & KVA & 26.395 & 27.265 & 27.915 & \\
\hline \multirow{2}{*}{11} & \multirow{2}{*}{ NOVEMBER } & BUAH & 242 & 247 & 249 & \\
\hline & & KVA & 26.555 & 27.265 & 27.975 & \\
\hline \multirow{2}{*}{12} & \multirow{2}{*}{ DESEMBER } & BUAH & 242 & 247 & 249 & \\
\hline & & KVA & 26.555 & 27.265 & 27.975 & \\
\hline
\end{tabular}




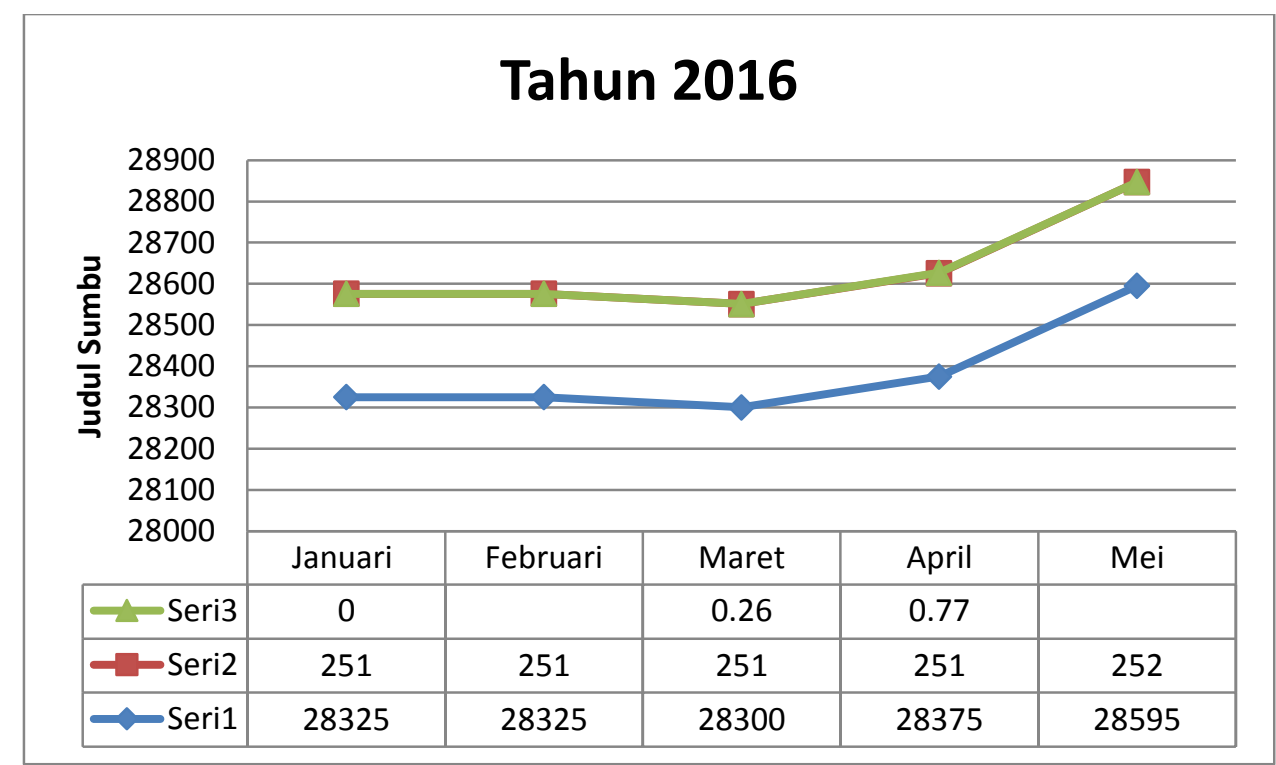

Gambar 4. Grafik hasil perkiraan laju pertumbuhan Beban (KVA) pada transformator distribusi di PT.PLN (Persero) Area Kediri UPJ Rayon Srengat - Blitar.

\subsection{Pembahasan}

1. Cara menentukan beban transformator distribusi yang mengalami overload didaerah Ponggok Desa karangbendo

a. Perkiraan pada bulan April 2016 di penyulang Maliran kecamatan Ponggok di desa Karangbendo. Sebelum penggantian transformator yang terpasang 50KVA, dengan nomor gardu EE 372, Maka penulis menggunakan rumus sebagai berikut:

$\mathrm{KVA}=\frac{\text { Rata }- \text { rata tegangan } x \text { jumlah beban }}{1000}$

$\mathrm{KVA}=\frac{900 \times 44}{1000}=39,6 \mathrm{KVA}$

Karena beban mendekati $80 \%$, maka transformator sebaiknya diganti yang lebih besar yaitu $75 \mathrm{KVA}$. Rumus yang digunakan digunakan untuk perhitungan rating transformator yang dipilih, (Warman, 2004):

Rating trafo $=\frac{\text { jumlah }(\mathrm{kva})}{0,8}$

Atau menggunakan rumus : Jumlah (KVA) $\frac{\text { Persen }}{100}=50 \frac{80}{100}=40 \mathrm{KVA}$

Bila Transformator terpasang $75 \mathrm{KVA}$ maka transformator tersebut dirumuskan :

Rating trafo $=\frac{\text { jumlah }(k v a)}{0,8}$

Atau : Jumlah (KVA) $\frac{\text { Persen }}{100}=75 \frac{80}{100}=60 \mathrm{KVA}$

$60 \mathrm{KVA}-39,6 \mathrm{KVA}=20,4 \mathrm{KVA}$

Jadi pemambahan transformator 20,4 KVA

\section{b. Menghitung Fuselink}

Fuse link $=\frac{P}{V \cdot \sqrt{3}}$ 
Menghitungfuselink:

$\begin{array}{ll}\text { Kapasitas } & =50 \mathrm{KVA}=50.000 \text { Volt } \\ \text { Tegangan TM } & =20 \mathrm{KV} / 231-400 \text { Volt } \\ \text { JenisTrafo } & =3 \mathrm{fasa} \\ \text { Jumlah jurusan } & =4 \text { Jurusan }\end{array}$

Jawab :

Fuse Link $=\frac{50000 \mathrm{VA}}{400 \times 1,73}=\frac{5000050000 \mathrm{VA}}{692}=72,22$ Amper

$$
=\frac{72,25}{4}=18,06 \text { Amper }
$$

Karena Fuse yang dipilih $=18,06$ x 0,9 = 16,25 Amper (beban $90 \%$ ), maka trafo yang dipasang nanti 20 Ampere.

menghitung fuselink:

$$
\begin{array}{ll}
\text { Kapasitas } & =75 \mathrm{KVA}=75.000 \text { Volt } \\
\text { Tegangan TM } & =20 \mathrm{KV} / 231-400 \text { Volt } \\
\text { JenisTrafo } & =3 \text { fhasa } \\
\text { Jumlah jurusan } & =4 \text { Jurusan }
\end{array}
$$

Jawab

$$
\begin{aligned}
& \text { Fuse Link }=\frac{75000 \mathrm{VA}}{400 \times 1,73}=\frac{75000 \mathrm{VA}}{692}=108,38 \text { Amper } \\
& \frac{108,38}{4}=27,09 \text { Amper }
\end{aligned}
$$

Karena Fuse yang dipilih $=27,09$ x 0,9 $=24,38$ Amper (beban $90 \%$ ), maka trafo yang dipasang nanti 25 Amper.

c. Untuk mengatisipasi beban lebih maka trafo distribusi diganti dengan trafo yang lebih besar kapasitasnya

\section{Cara menentukan beban transformator distribusi yang mengalami beban over load di daerah Udanawu desa Karanggondang.}

a. Perkiraan pada bulan Mei 2016 di penyulang Srengat kecamatan Udanawu di desa Begelenan (karanggondang) Sebelum penggantian transformator yang terpasang100 KVA, dengan nomor gardu EE 001, Maka digunakan rumus sebagai berikut:

$$
\begin{aligned}
\mathrm{KVA} & =\frac{\text { Rata }- \text { rata } \text { Teganganxjumlah beban }}{1000} \\
\mathrm{KVA} & =\frac{1300 \times 62}{1000}=80,6 \mathrm{KVA}
\end{aligned}
$$

Karena beban lebih $80 \%$, maka transformator sebaiknya diganti yang lebih besar yaitu $160 \mathrm{KVA}$.

rumus yang digunakan untuk perhitungan rating transformator yang dipilih, (Warman, 2004):

Rating trafo $=\frac{\text { jumlah }(\mathrm{kva})}{0,8}$

Atau menggunakan rumus : Jumlah (KVA) $\frac{\text { Persen }}{100}=100 \frac{80}{100}=80 \mathrm{KVA}$

Bila Transformator terpasang $160 \mathrm{KVA}$ maka transformator tersebut dirumuskan: 
Rating trafo $=\frac{\text { jumlah }(k v a)}{0,8}$

Atau : Jumlah $(\mathrm{KVA}) \frac{\text { Persen }}{100}=160 \frac{80}{100}=128 \mathrm{KVA}$

Maka penambahan transformator

$128 \mathrm{KVA}-80,6 \mathrm{KVA}=47,4 \mathrm{KVA}$

Jadi pemambahan transformator 47,4 KVA

b. Menghitung Fuselink

Fuse link $=\frac{P}{V \cdot \sqrt{3}}$

Cara menghitungfuse link=

$\begin{array}{ll}\text { Kapasitas } & =100 \mathrm{KVA}=100.000 \text { Volt } \\ \text { Tegangan TM } & =20 \mathrm{KV} / 231-400 \text { Volt } \\ \text { JenisTrafo } & =3 \text { fasa } \\ \text { Jumlah jurusan } & =4 \text { Jurusan }\end{array}$

Fuse Link $=\frac{100000}{400 \times 1,73}$ $=\frac{100000}{692}=144,50 \mathrm{Amper}$ $\frac{144,50}{4}=36,12$ Amper

Karena Fuse yang dipilih $=36,12 \times 0,9=32,51$ Amper (beban $90 \%$ ), maka trafo yang dipasang nanti 50 Amper.

$$
\begin{aligned}
& \frac{160000}{692}=231,2 \text { Amper } \\
& \frac{231,2}{4}=57,8 \text { Amper }
\end{aligned}
$$

Karena Fuse yang dipilih $=57,8 \times 0,9=52$ Amper (beban $90 \%$ ), maka trafo yang dipasang nanti 60 Amper.

b.Perkiraan pada bulan Mei 2016 di penyulang Srengat kecamatanSrengat di desa Dermojayan. Sebelum penggantian transformator yang terpasang 50KVA, dengan nomor gardu EE 397, Maka perencanaan yang akan dibutuhkan memakai rumus sebagai berikut:

$\mathrm{KVA}=\frac{\text { Rata-rata tegangan } x \text { jumlah beban }}{1000}$

$\mathrm{KVA}=\frac{1300 \times 32}{1000}=41,6 \mathrm{KVA}$

$\mathrm{KVA}=\frac{1300 \times 46}{1000}=59,8 \mathrm{KVA}$

Karena beban50 KVA melebihi $80 \%$,pada tabel data yang diperlukan kurang lebih $60 \mathrm{KVA}$ dan ukuran tersebut tidak ada di pasaran maka transformator dipasang sebesar $75 \mathrm{KVA}$.

Karena rumus yang digunakan untuk perhitungan rating transformator yang dipilih, (Warman, 2004):

Rating trafo $=\frac{\text { jumlah }(\mathrm{kva})}{0,8}$

Atau menggunakan rumus : Jumlah (KVA) $\frac{\text { Persen }}{100}=$ $75 \frac{80}{100} 60 \mathrm{KVA}$

c. Untuk mengatisipasi beban lebih maka trafo distribusi diganti dengan trafo yang lebih besar kapasitasnya.

b. Menghitung Fuselink 
Fuse link $=\frac{P}{V \cdot \sqrt{3}}$

Cara menghitungfuselink:

$$
\begin{array}{ll}
\text { Kapasitas } & =50 \mathrm{KVA}=50.000 \text { Volt } \\
\text { Tegangan TM } & =20 \mathrm{KV} / 231-400 \text { Volt } \\
\text { JenisTrafo } & =3 \mathrm{fasa} \\
\text { Jumlah jurusan } & =4 \text { Jurusan }
\end{array}
$$

Jawab :

$$
\begin{gathered}
\text { Fuse Link }=\frac{50000 \mathrm{VA}}{400 \times 1,73}=\frac{50000}{692}=72,22 \text { Amper } \\
=\frac{72,25}{4}=18,06 \mathrm{Amper}
\end{gathered}
$$

Karena Fuse yang dipilih $=18,06$ x 0,9 = 16,25 Amper (beban $90 \%$ ), maka trafo yang dipasang nanti 20 Amper.

Cara menghitung fuselink:

$\begin{array}{lll}\text { Kapasitas } & = & 75 \mathrm{KVA}=75.000 \text { Volt } \\ \text { Tegangan TM } & = & 20 \mathrm{KV} / 231-400 \text { Volt } \\ \text { JenisTrafo } & = & 3 \mathrm{fasa} \\ \text { Jumlah jurusan } & = & 4 \text { Jurusan }\end{array}$

Jawab

$$
\begin{aligned}
& \text { Fuse Link }=\frac{75000}{400 \times 1,73}=\frac{75000}{692}=108,38 \text { Amper } \\
& \frac{108,38}{4}=27,09 \text { Amper }
\end{aligned}
$$

Karena Fuse yang dipilih $=27,09 \times 0,9=24,38$ Amper (beban $90 \%$ ), maka trafo yang dipasang nanti 25 Amper.

c. untuk mengatisipasi beban lebih maka transformator tersebut diganti yang lebih besar.

keterangan : 1,73 diperoleh dari akar 3. karena trafo tersebut adalah trafo 3 phase, factor kali 0,8 adalah faktor keamanan pada beban trafo

\section{KESIMPULAN}

Dari hasil penelitian dan pembahasan, maka dapat ditarik suatu kesimpulan bahwa Laju pertumbuhan beban transformator distribusi yang ada di PT. PLN Srengat pada tahun 2013 adalah pada Januari-Februari mengalami peningkatan 0,38 \%, bulan Mei-Juni mengalami peningkatan 0,58\%, bulan September-Oktober mengalami peningkatan 1,14\%, pada tahun 2014 hanya dua kali peningkatan bulan Maret-April 0,94\% dan bulan September-Oktober 0,36\%. Pada tahun 2015 bulan Mei-Juni mengalami peningkatan 0,69\%, pada bulan JuliAgustus mengalami penurun-0,97\%, September-Oktober 1,71\%. Pada tahun 2016 bulan Maret-April mengalami peningkatan 0,26\% dan pada bulan April mengalami peningkatan $0,77 \%$.

Cara menentukan beban yang menalami beban transformator distribusi yang overload menggunakan rumus:

$$
K V A=\frac{\text { Rata }- \text { rata tegangan } x \text { jumlah beban }}{1000}
$$




$$
\text { Rumus cara mnentukan fuselink }=\frac{P}{V \times \sqrt{3}} \text {, fuselink tersebut tidak lebih dari } 90 \% \text {. }
$$

Transformator distribusi ini mengalami penurunan pada bulan Juli-Agustus 2015, dan pada bulan September-Oktober mengalami kenaikan. Apabila transformator tersebut tidak ganti dengan kapasitas yang lebih besar maka dapat merugikan pihak PLN. Beban lebih dpat diantisipasi dengan diadakan pengukuran, dan transformator tersebut diganti yang lebih besar pemakianya tidak lebih dari $80 \%$.

Sebelum memperkirakan daya maksimum sebaiknya terlebih dahulu dipelajari sifat kecenderungan data masa lalu sehingga total beban yang akan datang dapat diperkirakan dengan kecenderungan yang sama.

Perencanaan pengadaan transformator distribusi baru sebaiknya dilakukan setelah beban mencapai $80 \%$ dari kapasitas rating. Hendaknya dilakukan pemeliharaan berkala terhadap transformator distribusi untuk menjaga keandalan pasokan energi listrik. Akan lebih baik jika dibuatkan standart operasional prosedur (SOP) untuk operasi dan pemeliharaan.

\section{REFERENSI}

1. Muhammadlu, 2010: Bab II Landasan Teori, Proses penyaluran tenaga listrik, http://digilib.unimus.ac.id/files/disk1/132/jtptunimus-gdl-muhammadlu-6551-3babii.pdf, diakses 09 Mei 2016

2. Bastanna Erlayas Bangun, 2010: Studi Penempatan Transformator Distribusi Berdasarkan Jatuh Tegangan (Studi Kasus. Pada PT. PLN (Persero) Rayon Medan.http://repository.usu.ac.id/bitstream/123456789/11831/1/10E00098.pdf, diakses 27 Oktober 2016.

3. Ca. Lestari, 2015, Sistem Distribusi Tenaga Bab II, Palembang-Sumsel http://eprints.polsri.ac.id/1742/3/BAB\%20II.pdf, diakses 09 Mei 2016

4. Hana Kres, 2014: Cara menghitung berapa Ampere NH Fuse yang harus dipasang adalah ... Lihat juga: Gambar Ukuran DanFungsi Fuse Link Sebagai Pemutus. http://materiallistrik.blogspot.co.id, diakses 13 September 2016.

5. Data Trafo 2016, PT.PLN (Persero)Area kediri UPJ Rayon Srengat-Blitar 